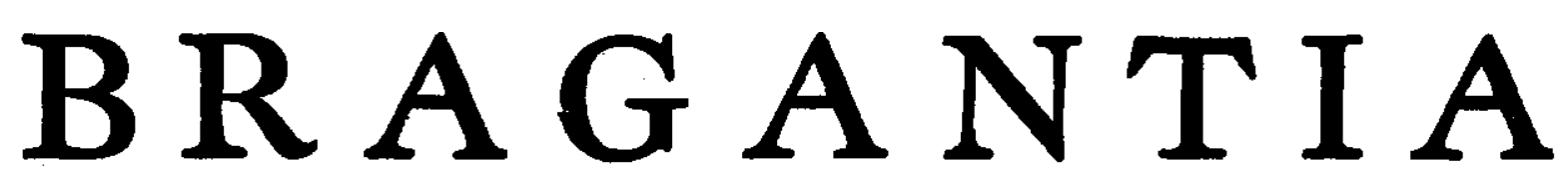

Boletim Técnico da Divisão de Experimentação e Pesquisas I N S T I T UTO A G R O NOM I CO

Vol. 2

Campinas, Agosto de 1942

N. 8

\title{
COMPORTAMENTO DE VARIEDADES E PROGÊNIES DE FUMO NA RESISTENCIA AO "VIRA-CABEÇA"
}

\author{
F. G. Brieger, A. Rodrigues Lima \\ R. Forster
}

\section{INTRODUÇÃO}

Nas experiências genéticas com fumo, como, aliás, no caso de qualquer outra planta, tornou-se necessário o uso de algumas variedades como "standard" testemunhas para indicar o modo sobre o qual devemos prosseguir os trabalhos de melhoramento e se estes devem ser considerados satisfatórios. A principal das doenças que dificultam os nossos trabalhos é o "vira-cabeça" (3) e, consequentemente, variedades relativamente resistentes a ele deviam ser escolhidas. Observações prévias indicaram, como mais resistentes, os tipos "Sumatra" e "Virgínia", e os primeiros ensaios comparativos realizados para isto comprovar, deram 0 mesmo resultado $(1 \in 4)$. Assim, tornou-se desejavel comparar em mais detalhe as diferentes linhagens destas variedades na coleção de fumo do Instituto Agronômico. Não nos limitamos à questão de resistência contra "vira-cabeça", mas, tambem, contra dois outros virus importantes, o mosaico $\left(^{*}\right)$ e a doença denominada "necrose branca-couve". Tambem foram estudados caracteres morfológicos, como altura da planta, número das folhas, largura e comprimento das mesmas.

Incidentalmente, a experiência aquí relatada serve tambem para outro fim. As plantas de Nicotiana tabacum são, geralmente, propagạdas por autofecundação natural, de modo que devemos esperar que

(") Como mosaico anotamos, indistintamente, tanto o do Nicotiana virus 1, como o do Cucumis virus 1. Não é possivel distingúl-los em campo. 
as linhagens sem uma intervenção por cruzamento artificial, sejam altamente homogêneas. Assim, a conservação de muitas progênies paralelas será dispensavel. Mas antes de abandonar esta prática em uso no Instituto Agronômico, ensaios exatos pareciam indicados.

Uma vez que em geral nada se sabe sobre as variedades antes da sua inclusão na coleção, não se pode ter certeza sobre sua homogeneidade. De-fato, no mínimo uma delas, Sumatra V 176, segregou claramente, para um carater da flor, calicantemia recessiva, e não sabemos se se trata de uma mutação mais recente ou de uma segregação que segue a um cruzamento de modo que a linhagem pode ser heterogênea com respeito a outros caracteres.

Finalmente, foi tentada no curso destas experiências uma seleção para maior resistência contra o virus do "vira-cabeça".

O objetivo principal deste trabalho é a avaliação dos dados colhidos num ensaio bastante detalhado, feito em 1940/41. Foi-nos possivel usar algumas observações colhidas em ensaios preliminares, executados em 1936/37, e dados de um ensaio da Seç̧ão de Fumo do Instituto Agronômico, realizado em 1937/38.

Observações de 1936/37 : Foram feitas algumas observações em Campinas sobre a ocorrência de plantas com "vira-cabeça", num ensaio de variedades. $O$ número de plantas atacadas foi anotado para as variedades Virgínia Bright (V-l) e para cinco tipos de Sumatra. Os resultados indicaram uma infeção de, aproximadamente, $30 \%$ de plantas atacadas para a var. 1, enquanto três dos tipos Sumatra tiveram uma infeção abaixo e dois acima de 5\%.

\section{EXPERIÊNCIA DE $1938 / 39$}

\section{a) Plano geral}

A experiência do ano de $1938 / 39$ pode apenas ser considerada como preliminar. Progênies de 7 diferentes tipos de "Sumatra" de origens diferentes foram plantadas.

Plantas de "Virgínia" foram usadas como controles, intercalando-se entre fileiras de "Sumatra" 21 linhas de "Virgínia" com 34,6 plantas em média. Esperando uma uniformidade satisfatória das progênies de "Virgínia", foram semeadas sementes misturadas de diferentes progênies.

Nos parágrafos seguintes vamos discutir, rapidamente, a infeção das plantas pelas doenças mais importantes: "Vira-Cabeça" e "Mosaico".

\section{b) Comportamento dos controles "Virgínia".}

Um teste "entre-dentro linhas" demonstra claramente a homogeneidade da infeção, podendo-se daí concluir que as condições do terreno 
em geral e da infeção foram bastante uniformes na área experimental.

Em média achou-se nas 21 linhas "Virgínia" uma infeção de 57,1\% de "Vira-cabeça" com erro "standard" da distribuição de $\pm 15,0 \%$ e de 6,6\% de "Mosaico" com erro "standard" da distribuição de $\pm 8,1 \%$.

\section{c) Comportamento da var. "Sumatra"}

Sobre a resistência destas linhagens em relação ao virus "viracabeça", havia alguns dados preliminares do ano 1937/38. Os resultados dos dois anos, 1937/38 e 1938/39, estão reunidos no quadro I. Não pode haver dúvida de que as 7 variedades são bastante diferentes entre si. Três são muito pouco ou não resistentes: V-17, V-18 e V-176; quanto às outras, são um pouco mais resistentes, com uma infeção abaixo de $25 \%$, em $1937 / 38$, e de $40 \%$, em 1938/39.

As 27 linhagens de V-38 em 1938/39, podem ser agrupadas em 5 grupos de acordo com as famílias de 1937/38. O teste "entre-dentro" mostrou grande heterogeneidade, com o erro "entre" de $\pm 22,36$ em comparação com o erro "dentro" de $\pm 8,63$. O erro residual é ainda grande, porem menor do que nas linhas controle "Virgínia".

A resistência contra mosaico, tambem não é a mesma para as diferentes linhagens. De acordo com o teste "entre-dentro" podemos distinguir dois grupos: var. 17-38-43-114 com 11 a 16\%, e var. 18-39 com 0 a $5 \%$ de infeção.

É interessante notar que não há correlação entre a infeção das duas doenças. A variedade não atacada por mosaico, foi uma das mais atacadas pelo "vira-cabeça".

\section{A EXPERIÊNCIA DE 1940/41}

\section{1) - Plano experimental.}

Baseado nos resultados das experiências preliminares foi elaborado o seguinte plano final:

De "Sumatra" foram incluidas progênies de V-38, V-39, V-43 e V-1 14. Das três últimas foi tomada uma progênie, cada vez, de 1937/38, 3 progênies em 1938/39. Neste ano, mais uma vez, três plantas em cada uma das 3 progênies por variedade, foram autofecundadas de modo que tínhamos finalmente para 1940/41, 9 progênies por variedade, sendo três cada vez derivadas de plantas irmãs, e os três grupos de três destes por sua vez representam primos (quadro II).

De V-38 foram escolhidas 2 progênies de 1937/38 e o plano foi o de serem utilizadas de cada uma delas, 3 progênies em 1938/39. Mas, 
como mostra o quadro II, da progênie 1.292-1937/38 havia somente duas plantas autofecundadas que deram, então, as famílias 2.036-e 2037 - 1938/39. Quando de todas as famílias deste ano foram autofecundados três indivíduos, ficaram na família 2.037 - 1938/39 6 plantas selecionadas. Assim, obtiveram-se tambem de Sumatra, finalmente, 6 grupos, de 3 famílias cada um, para 1940/4l (quadro II).

Podemos desse modo usar os seguintes agrupamentos para a análise estatística : 5 linhas em 1937/38, dando 4 graus de liberdade, 14 linhas de $1938 / 39$, contribuindo $14-5=9$ graus de liberdade e $15 \times 3=45$ linhas em 1940/41, contribuindo $45-14=31$ graus de liberdade. Não devemos, porem, esquecer que duas da primeira linhagem de $1937 / 38$ são mais afins do que as demais, pertencendo ambas à $\mathrm{V} 38$, e que 2 grupos de 3 linhagens de 1940/41 são tambem mais relacionados do que os demais, sendo derivados da mesma linha 2.037 de 1938/39. (Quadro II).

Da variedade V-1, "Virgínia", foram usadas 3 famílias em 1936/37. Destas foram derivadas, em 1938/39, por autofecundação, 6 progênies, como está indicado no quadro III. Assim, finalmente, foram obtidos 6 grupos de 3 famílias irmãs em 1940/41, como indica o quadro III. Este total de 18 famílias continha, na análise, os seguintes graus de liberdade: 2 graus de liberdade correspondem às 3 progênies de $1936 / 37$. As famílias, em $1938 / 39$, dão $6-3=3$ graus de liberdade e, finalmente, teremos $6 \times 3=18$ famílias irmãs em 1940/41, que dão $18-6=12$ graus de liberdade (quadro VI).

Estes agrupamentos devem dar uma decomposição dos erros aproximadamente de acordo com o grau de parentesco das diferentes progênies em estudo no ano 1940/41.

Para analisar o efeito do terreno, foi usado o seguinte processo: A área total de $3.704 \mathrm{~m}^{2}$ foi dividida em 9 blocos, cada um de 21 parcelas: : 15 para progênies de "Sumatra" e 6 para "Virgínia". A distribuição das famílias que está indicada no quadro IV foi arranjada pelo mesmo processo como num quadrado latino de $3 \times 3$, de modo que as colunas $A, B, C$ e linhas I, II e III, representam repetições completas. Os blocos IA, IIC, e IIIB, os blocos IB, IIA e IIIC, os blocos IC, IIB e IIIA, são idênticos. Estes 3 grupos comparados entre si conteem famílias irmãs, por exemplo, $4371 \mathrm{em} \mathrm{IA,} \mathrm{etc.,} 4392 \mathrm{em}$ IIB e 4413 em IC, etc. (Quadros II e IV).

O caminho normal de análise de um tal quadrado latino consiste em dividir os 9-1 = 8 graus de liberdade em quatro partes : 2 entre "colunas", 2 entre "linhas", 2 entre os grupos de progênies e 2 para 
as interações residuais. Sacrificando, porem, a comparação entre estes 3 grupos de progênies irmãs, foram reunidos 4 graus de liberdade para a interação.

Temos assim a decomposição de efeito do terreno com um total de 8 graus de liberdade e a decomposição genética com 44 graus de liberdade para "Sumatra" e 18 para "Virgínia".

Tomando-se em consideração as 3 repetições completas, temos um total de grau de liberdade para "Sumatra" de 45 × $3=135$ menos 1 ou 134 e para "Virgínia" de 18 × $3=54$ menos 1 ou 53. Ficam, portanto, para a interação Repetição-linhagens para "Sumatra" (45 × $3=$ ) $134-8-44=82$ e para "Virgínia" 53-8-17 = 28 graus de liberdade.

As medidas, altura da planta, número, comprimento e largura das folhas foram tomadas de 5 plantas de cada parcela. Isto devia ter dado $4 \times 135=540$ graus de liberdade no caso de "Sumatra" e 4 × $54=216$ graus de liberdade de "Virgínia". Mas, em consequência de enganos na execus: oo da experiência, uma parcela de "Sumatra" tinha que ser excluida, obtendo-se assim para a "interação" apenas $81 \mathrm{em}$ vez de 82 graus de liberdade e para o resíduo, 535 em vez de 540 .

$\mathrm{Na}$ análise da infeção, o número ou percentagem de plantas doen. tes ou sãs por canteiro forma a base dos cálculos. Assim, temos 134 parcelas de "Sumatra" e 54 de "Virgínia".

Decompondo a variação total paralelamente à decomposição dos graus de liberdade, obtivemos os resultados que constam dos quadros $\mathrm{V}$ e VI. Todavia, com referência à infeção nas parcelas, surgiu uma complicação. Somente no caso da infeção de "vira-cabeça" em "Sumatra", na experiência de Campinas, a percentagem de plantas doentes na média era de tal vulto $(64 \%)$ a permitir esta forma de análise. Nos outros casos, entretanto, o número de plantas doentes ou sãs foi tão pequeno que não se podia esperar uma distribuição normal de percentagens, mas uma distribuição de Poisson dos números ou frequências.

\section{2) - Caracteres vegetativos das plantas :}

Nos quadros $\mathrm{V}$ e VI constam os resultados da análise estatística com referência a cinco caracteres da planta : altura do chão até a primeira cápsula, número de folhas, excluindo-se nesta determinação as folhas pequenas da região da inflorescência, comprimento e largura média de cinco folhas tiradas do meio de cada planta e o índice, largura e comprimento.

Estas medidas foram tiradas de cinco indivíduos em cada uma das parcelas, mas notamos, durante a análise, que o erro "residual" assimı 
obtido era muito pequeno. A causa foi uma seleção de plantas, forte demais. Em vez de excluir apenas plantas atualmente doentes, as medidas foram feitas em plantas que desviavam um mínimo da média de cada parcela. Para isto provar, foram medidas todas as plantas sãs de algumas parcelas e os erros assim obtidos (penúltima linha nos quadros $\mathrm{V}$ e VI) foram, de-fato, mais ou menos duas vezes maior do que aqueles das medidas de plantas selecionadas. $O$ encarregado destas medições mostrou a sua eficiência em selecionar plantas uniformes, porem o valor do erro assim obtido não pode ser usado na análise, por ser artificialmente reduzido em tamanho. Empregamos o erro entre as plantas não selecionadas como erro de acaso das experiências.

A decomposição, realizada de acordo com o acima exposto, separou, em primeiro lugar, duas partes : decomposição do terreno e decomposição genética.

O terreno mostrou-se razoavelmente homogêneo a-pesar do aparecimento de alguns valores de $\vartheta$ significantes.

A decomposição genética revelou uma certa heterogeneidade, num grau maior no caso de "Sumatra" do que em "Virgínia". Valores do erro demasiadamente grande aparecem no componente que corresponde ao agrupamento de progênies de acordo com seus antecedentes em 1937/38 (comparar com quadro III). Entretanto, em consideração ao número bem elevado de plantas que foram reunidas nestes poucos grupos, devemos esperar uma constância extremamente grande das respectivas médias, de ordem de $1 \mathrm{~cm}$ para a altura da planta, de um décimo de uma folha para o número de folhas, etc.

Atualmente, as médias obtidas podiam ser consideradas como suficientemente constantes, como mostram os dados abaixo e a sua variação estatisticamente excessiva como sendo sem importância.

\section{"SUMATRA" :}

Altura da planta

Número de folhas

\begin{tabular}{|c|c|}
\multicolumn{2}{c|}{$\mathrm{V} 38$} \\
189,2 & 189,3 \\
26,3 & 25,9 \\
37,2 & 38,2 \\
21,2 & 22,8 \\
0,57 & 0,60
\end{tabular}

$\mathrm{V} 39$
187,7
25,9
37,9
22,3
0,59

$\mathrm{V} 43$
186,0
25,9
36,8
21,1
0,57

V 114

Comprimento das folhas $(\mathrm{cm})$

Ĺndice

$\left|\begin{array}{c}503 / 504 \\ 167,2 \\ 22,8 \\ 44,5 \\ 24,6 \\ 0,55\end{array}\right|$

542
164,2
23,3
44,1
22,7
0,52

512
170,9
22,8
44,5
25,0
0,56

185,4 
Esta grande constância das médias demonstra a inutilidade de se manter no fumo um número elevado de progênies. Se o material recentemente importado já se mostra tão razoavelmente homogêneo na primeira autofecundação, não é necessário fazer mais seleção e manter diferentes progênies.

\section{3) - Resistência entre doenças}

O "stand" inicial era bem grande e constante nesta experiência, de modo que a determinação da infeção podia ser satisfatória. As respectivas médias, e erros da distribuição são enumerados abaixo:

\begin{tabular}{l|c|c|c} 
& N.o de & "Stand" & Erro \\
parcelas & Média geral & "standard" \\
"Sumatra" - Limeira ...... & 134 & 41,0 & $\pm 3,56$ \\
"Sumatra" - Campinas . . . & 132 & 34,8 & $\pm 5,22$ \\
"Virgínia" - Limeira ...... & 54 & 43,6 & $\pm 0,74$ \\
"Virgínia" - Campinas .... & 49 & 32,6 & $\pm 6,58$
\end{tabular}

Em consequência de enganos na plantação das mudas no campo, em Campinas, alguns canteiros tinham que ser excluidos por conter misturas de plantas em vez de indivíduos de uma só progênie. Assim, ficaram perdidos 3 canteiros de "Sumatra" e 5 de "Virgínia".

"Vira-cabeça" - A percentagem de infeção foi em Campinas bastante grande: $64 \%$ para "Sumatra" e 90\% para "Virgínia". A percentagem no "Sumatra" é ainda tal que permite tratar as percen. tagens como simples variaveis e proceder à análise de decomposição pelo modo acima explicado. Nenhuma componente (quadro VII) foi significante, indicando que o terreno não tinha nenhum efeito e que, nas condições desta experiência, todas as progênies são igualmente pouco resistentes. Calculando o erro ideal pela fórmula:

$$
\sigma_{1}= \pm \sqrt{\mathrm{p} \%(100-\mathrm{p} \%) \mathrm{n}}
$$

onde $\mathrm{p} \%$ é a percentagem de plantas doentes e $\mathrm{n}$ é o número de plantas "stand" por parcela, obteremos o valor de $\pm 8,15 \%$, que é apenas pouco menor do que o valor atualmente obtido de $\pm 12,32 \%$.

A infeção de "Virgínia" é tão grande, que apenas poucas plantas ficaram sãs e não podemos tratar das percentagens, mas, sim, esperar que a frequência (número) de plantas sãs seguisse uma distribuição de Poisson. Apenas um $\mathrm{X}^{2}$ - teste foi feito (quadro VIII). Comparando as frequências observadas e esperadas obteremos valores de $\mathrm{X}^{2}$ grandes demais, com um excesso das parcelas com nenhuma ou apenas uma 
planta doente. Separando o terreno em seus sub-blocos (colunas A, $B$ e C) notamos que estes são diferentes. Não podemos, para estes, executar um $\mathrm{X}^{2}$ para cada um dos sub-blocos, em consequência do pequeno número de parcelas. Mas, comparando o erro "standard" diretamente determinado pelas duas fórmulas:

Fórmula direta

$$
\tau= \pm \sqrt{\frac{\sum\left[\mathrm{f} \text { obs. }-\mathrm{f}(\text { média })^{2}\right]}{n-1}}
$$

onde $\mathbf{n}$ é o número de parcelas, e

\section{Fórmula ideal $\quad \sigma$ (Poisson) $= \pm \sqrt{\mathrm{f} \text { (média) }}$}

verificamos que os primeiros são apenas ligeiramente maiores do que os valores ideais para os sub-blocos, quando o valor de $\theta$ era bastante significante para o total. (Quadro IX, penúltima linha). Daí podemos concluir que as distribuições nos sub-blocos seguem o teorema de Poisson, e que a irregularidade do total é provocada pelo fato de que não combinam os valores dos sub-blocos que seguem distribuições de Poisson, com médias diferentes. De-fato, os valores de $\mathbf{t}$ para a diferença entre as médias parciais dos sub-blocos são, sejam duvidosos, (entre 5 e 1\%), ou, significantes, (fora de 1\%). (Quadro IX).

Uma vez que a diferença entre sub-blocos somente pode ser atribuida a efeitos do terreno, podemos concluir que a resistência ou, melhor, a falta de resistência das progênies de "Virgínia", em Campinas, foi a mesma para todos, e unicamente alterada por fatores do terreno.

Em Limeira, encontramos uma infeção muito fraca, de modo que, mais uma vez, temos que fazer uma comparação com uma distribuição de Poisson. O quadro IX mostrou que não foi encontrada uma divergência : tanto o $\mathrm{X}^{2}$-teste, como a comparação entre os erros determinados diretamente com os valores ideais não deram nenhum valor significante. Mais uma vez chegamos à conclusão de que as progênies destas duas variedades são bastante uniformes.

Sempre encontramos maior resistência em "Sumatra" do que em "Virgínia".

\section{4) - Mosaico e "couve"}

O número de plantas atacadas pelo virus de mosaico e de "couve" tambem foi determinado. $O$ primeiro não foi encontrado em nenhum indivíduo em Limeira, e, em geral, a infeção era bem fraca, como demonstrado pelos números médios por parcela. 
Número médio de plantas doentes :

\begin{tabular}{|c|c|c|}
\hline & Mosaico & Couve \\
\hline 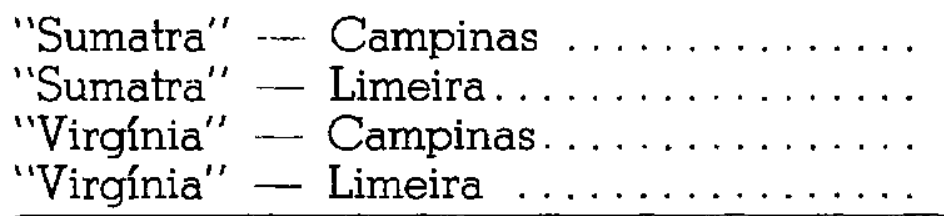 & $\begin{array}{l}1,43 \\
0 \\
0,50 \\
0\end{array}$ & $\begin{array}{l}5,82 \\
1,50 \\
2,17 \\
1,30\end{array}$ \\
\hline
\end{tabular}

Os números são tão pequenos que somente uma distribuição de Poisson podia ser esperada. Para os seis casos onde havia plantas doentes os números observados de plantas doentes por parcela seguiam, de-fato, este tipo de distribuição, como demonstrado pelo $\mathrm{X}^{2}$ - teste e a comparação do erro diretamente determinado e o erro ideal.

Daí podemos concluir que todas as progênies, tanto de "Sumatra" como na variedade "Virgínia", são uniformemente resistentes a essas duas doenças.

A resistência ao mosaico nesta experiência era, em geral, maior do que aquela contra "couve", e as progênies de "Virgínia" são ligeiramente mais resistentes do que as de "Sumatra".

\section{CONCLUSÕES}

1) - O fim da presente experiência foi uma comparação detalhada entre diferentes progênies de tipos de "Virgínia" e "Sumatra" da coleção do Instituto Agronômico, de origens diversas. Assim pretendíamos resolver se há dentro dessas duas variedades uma heterogeneidade suficiente e aproveitavel para uma seleção ou se, por outro lado, a homogeneidade é tão grande que poderíamos reduzir o número das atuais linhagens na coleção.

2) - A experiência preliminar de 1938/39 demonstrou que entre 7 diferentes introduções de "Sumatra" há, de-fato, diferenças bastante pronunciadas, especialmente quanto à resistência a "vira-cabeça". Em consequência da análise, somente progênies de 4 origens foram mantidas na experiência final.

3) - Na experiência final foi usada uma disposição experimental que permitiu uma análise estatística detalhada de efeitos do terreno e das possiveis diferenças genéticas entre progênies de parentesco de grau diferente.

4) - No estudo da infeção, porem, com exceção da percentagem de plantas atacadas de "vira-cabeça" em progênies "Sumatra" e em 
Campinas, uma análise detalhada não foi possivel em consequência do pequeno número de plantas sãs no caso de "vira-cabeça" em "Virgínia", e de plantas doentes no caso de ataque de mosaico e "couve". Pudemos unicamente aplicar um $\mathrm{X}^{2}$-teste para comparar a frequência de plantas doentes, por canteiro, com a frequência esperada numa distribuição correspondente de Poisson.

5) - O terreno mostrou-se relativamente uniforme.

6) - A respeito dos caracteres vegetativos (altura da planta, número de folhas e suas dimensões), havia diferenças estatísticamente significantes, porem (comparando as médias, pág. -- 280) sem a mínima importância prática.

7) -- Quanto à resistência à doença "vira-cabeça", todas as progênies dentro de cada variedade foram igualmente não resistentes, salvo um efeito do terreno significativo, mas pouco importante sobre "Virgínia", em Campinas. Ficou, porem, bem claro que as progênies "Sumatra" são mais resistentes que as de "Virgínia".

8) - A resistência contra mosaico e "couve" (pág. - 283) é por outro lado maior em "Virgínia" que em "Sumatra". Mas estas doenças nunca alcançaram importância nestas experiências.

9) - Em resumo, podemos dizer que não há justificação em se manter separadamente as progênies das formas de "Sumatra" incluidas nas experiências de 1940/41 nem tão pouco as de "Virgínia". Tambem os resultados de 1940/41 não deram esperança para melhorar, seja quanto a caracteres vegetativos, ou de resistência, por uma simples seleção.

\section{AGRADECIMENTO}

Ao sr. A. S. Costa agradecemos as anotações de moléstias feitas em Campinas, 1940/41.

\section{SUMMMARY}

1) The object of the experiment presented in this publication was a detailed comparison between progenies of the varieties Virginia and Sumatra of the collection of the Instituto Agronômico de Campinas. We intended to decide whether these strains were sufficiently heterogeneous to permit further selections or whether they were already so uniform as to allow a reduction in their number within our collection.

2) A preliminary experiment in $1939 / 40$ showed clearly that some of the 7 types introduced as Sumatra were less resistant than others, and the experiment was thus continued with only four of them.

3) The lay-out of the final experiment was such as to permit both a complete analysis of soil heterogeneity and of differences between the genetically different lines. Without confounding there were only 3 complete replications, but after confounding we may dispose of 8 degrees of freedom for replications. This method of decomposing the total variation was used in the analysis of the vegetative characters.

4) The analysis of disease resistance could follow the same lines only the case of the infection of Sumatra by "spotted will" (2). There the main percentage of infected 
plants per plot was $60 \%$, and the individual percentagens, without any further angular or other transformation, were used.

In all other cases the number either of diseased or of not disease plants per plot was so small that these frequencies could only be compared with the corresponding Poisson distribuition. For this propose either a $\mathrm{X}^{2}$ test was carried out or a comparison was only made between the error of a Poisson distribuition and the error directly determined from the data. variation.

5) The blocks were reasonably homogeneous, soil heterogeneity causing only minor

6) The plant characters such as height of plant, number of leaves and their dimensions showed a variation which was statistically significant, but without any practical importance as the data on pg. 280 show. The mean height was found to be $187,5 \mathrm{~cm}$ for Sumatra and $168,5 \mathrm{~cm}$ for Virginia the mean leaf number per plant - 25,7 and 22,8 - respectively and the mean index length of leaf - 37,3 and 44,4 - respectively.

7) All progenies within both varieties were equally little resistant against "spotted wilt", and soil heterogeneity caused a slight difference of resistance between the progenies of Virginia in Campinas. It is evident that the lines of Sumatra are more resistant than those of Virginia.

8) Infection by mosaic virus and the virus of "streak" (necrose branca-couve), was slight and the different progenies were equally resistant. As a whole, Virginia seems more resistant than Sumatra.

9) In short, there is a great homogeneity of the different lines of the varieties Sumatra and Virginia tested, and the prospect to their improvement by selection is negligible, both with regard to the vegetative characters studied or to disease resistance.

\section{LITERATURA CITADA}

1. Brieger, F. G. e outros. Ensaio de épocas de transplante para fumo. Bragantia, 2 : 295-312. Quadros I-VIII. 1942.

2. Costa, A. S. e R. Forster. Identidade do virus de "vira-cabeça" e sua inclusão no grupo do virus do "spotted-wilt". Bragantia, 1 : 491-506. Figs. 1-19. 1941.

3. Forster, R. e A. S. Costa. Nota preliminar sobre a moléstia "vira-cabeça" do fumo. Rev. Agricultura, Piracicaba, 13 : 69-78. Figs. 1-12. 1938.

4. Lima, Abelardo R. e A. S. Costa. Variedades de fumo resistentes a "vira-cabeça". Rev. Agricultura, Piracicaba, 15 : 133-140. Fig. 1. 1940. 


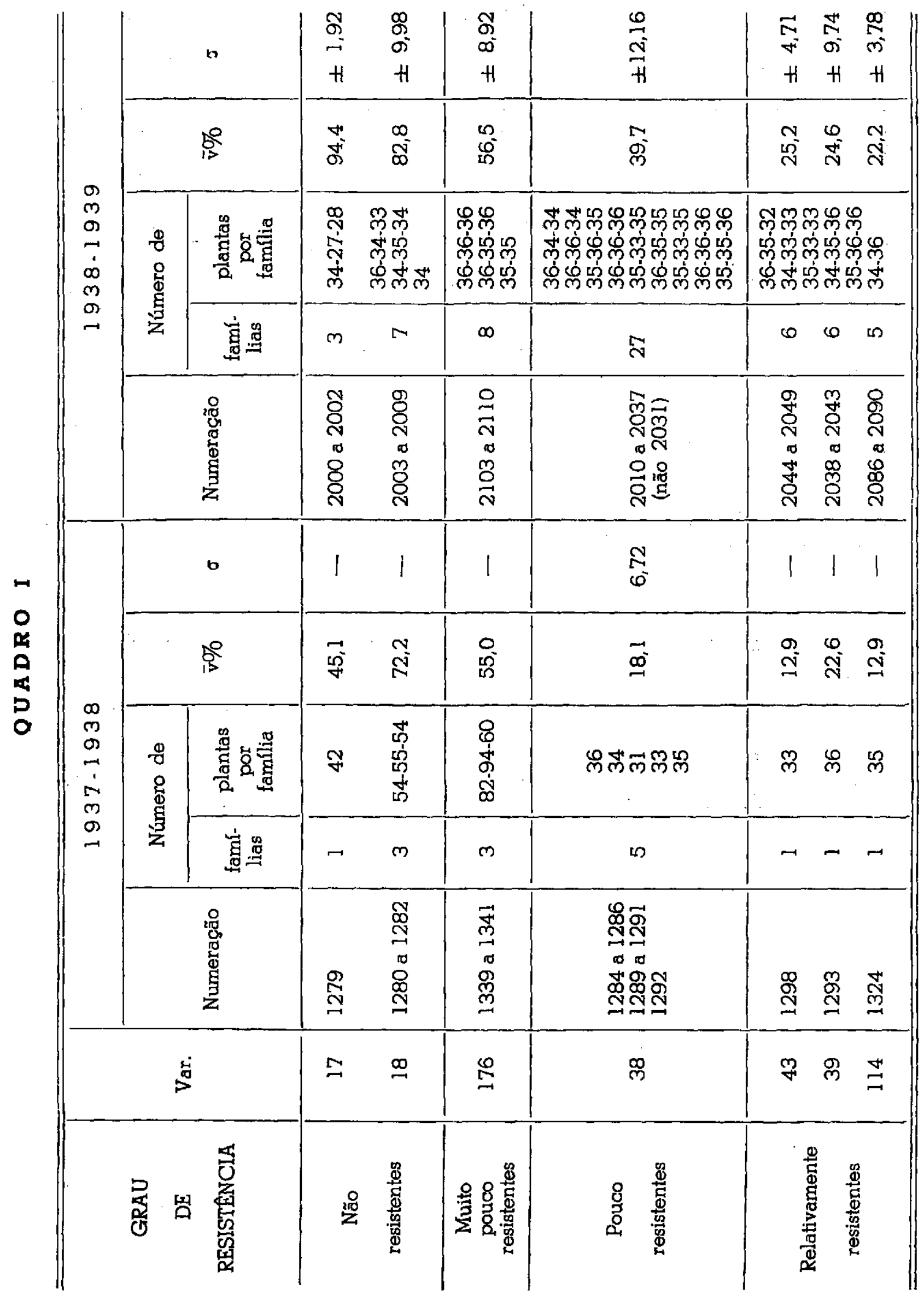




\section{QUADRO I I}

RELAÇAO DA VARIEDADE DE "SUMATRA" USADA EM 1940 E 1941

\begin{tabular}{|c|c|c|c|c|c|c|c|}
\hline ORIGEM & $\begin{array}{l}\text { N. }{ }^{\circ} \text { da } \\
\text { coleção }\end{array}$ & $1937 / 38$ & $1938 / 39$ & $1940 / 41$ & PLANTA & $\mathrm{O} \mathrm{EM}$ & BLOCO \\
\hline \multirow{6}{*}{$\begin{array}{l}\text { São-José } \\
\text { do-Rio- } \\
\text { Pardo } \\
\text { (1933) }\end{array}$} & \multirow{6}{*}{$V 38$} & \multirow{3}{*}{1.291} & 2.027 & $\begin{array}{l}4.371 \\
4.392 \\
4.413 \\
\end{array}$ & $\begin{array}{l}\text { AI } \\
\text { AII } \\
\text { AIII }\end{array}$ & $\begin{array}{l}\text { BIII } \\
\text { BI } \\
\text { BII }\end{array}$ & $\begin{array}{l}\text { CII } \\
\text { CIII } \\
\text { CI } \\
\end{array}$ \\
\hline & & & 2.029 & $\begin{array}{l}4.372 \\
4.393 \\
4.414\end{array}$ & $\begin{array}{l}\text { AI } \\
\text { AII } \\
\text { AIII } \\
\end{array}$ & $\begin{array}{l}\text { BIII } \\
\text { BI } \\
\text { BII } \\
\end{array}$ & $\begin{array}{l}\text { CII } \\
\text { CIII } \\
\text { CI }\end{array}$ \\
\hline & & & 2.030 & $\begin{array}{l}4.373 \\
4.394 \\
4.415 \\
\end{array}$ & $\begin{array}{l}\overline{A I} \\
\text { AII } \\
\text { AIII }\end{array}$ & $\begin{array}{l}\text { BIII } \\
\text { BI } \\
\text { BII } \\
\end{array}$ & $\begin{array}{l}\text { CII } \\
\text { CIII } \\
\text { CI }\end{array}$ \\
\hline & & \multirow{3}{*}{1.292} & 2.036 & $\begin{array}{l}4.374 \\
4.396 \\
4.417\end{array}$ & $\begin{array}{l}\text { AI } \\
\text { AII } \\
\text { AIII }\end{array}$ & $\begin{array}{l}\text { BIII } \\
\text { BI } \\
\text { BII }\end{array}$ & $\begin{array}{l}\text { CII } \\
\text { CIII } \\
\text { CI }\end{array}$ \\
\hline & & & \multirow{2}{*}{2.037} & $\begin{array}{l}4.375 \\
4.395 \\
4.416\end{array}$ & $\begin{array}{l}\text { AI } \\
\text { AII } \\
\text { AIII }\end{array}$ & $\begin{array}{l}\text { BIII } \\
\text { BI } \\
\text { BII }\end{array}$ & $\begin{array}{l}\text { CII } \\
\text { CIII } \\
\text { CI }\end{array}$ \\
\hline & & & & $\begin{array}{l}4.376 \\
4.397 \\
4.418 \\
\end{array}$ & $\begin{array}{l}\text { AI } \\
\text { AII } \\
\text { AIII } \\
\end{array}$ & $\begin{array}{l}\text { BIII } \\
\text { BI } \\
\text { BII } \\
\end{array}$ & $\begin{array}{l}\text { CII } \\
\text { CIII } \\
\text { CI } \\
\end{array}$ \\
\hline \multirow{3}{*}{$\begin{array}{c}\text { Buitenzorg } \\
\text { (Java) } \\
\text { (1933) }\end{array}$} & \multirow{3}{*}{ V 39} & \multirow{3}{*}{1.293} & 2.038 & $\begin{array}{l}4.377 \\
4.398 \\
4.419\end{array}$ & $\begin{array}{l}\text { AI } \\
\text { AII } \\
\overline{A I I I}\end{array}$ & $\begin{array}{l}\text { BIII } \\
\text { BI } \\
\text { BII }\end{array}$ & $\begin{array}{l}\text { CII } \\
\text { CIII } \\
\text { CI }\end{array}$ \\
\hline & & & 2.040 & $\begin{array}{l}4.378 \\
4.399 \\
4.420\end{array}$ & $\begin{array}{l}\text { AI } \\
\text { AII } \\
\text { AIII }\end{array}$ & $\begin{array}{l}\text { BIII } \\
\text { BI } \\
\text { BII }\end{array}$ & $\begin{array}{l}\text { CII } \\
\text { CIII } \\
\text { CI }\end{array}$ \\
\hline & & & 2.041 & $\begin{array}{l}4.379 \\
4.400 \\
4.421\end{array}$ & $\begin{array}{l}\text { AI } \\
\text { AII } \\
\text { AIII }\end{array}$ & $\begin{array}{l}\text { BIII } \\
\text { BI } \\
\text { BII }\end{array}$ & $\begin{array}{l}\text { CII } \\
\text { CIII } \\
\text { CI }\end{array}$ \\
\hline \multirow{3}{*}{$\begin{array}{c}\text { Buitenzorg } \\
\text { (Java) } \\
\text { (1933) }\end{array}$} & \multirow{3}{*}{ V 43} & \multirow{3}{*}{1.298} & 2.044 & $\begin{array}{l}4.380 \\
4.401 \\
4.422\end{array}$ & $\begin{array}{l}\text { AI } \\
\text { AII } \\
\text { AIII }\end{array}$ & $\begin{array}{l}\text { BIII } \\
\text { BI } \\
\text { BII }\end{array}$ & $\begin{array}{l}\text { CII } \\
\text { CIII } \\
\text { CI }\end{array}$ \\
\hline & & & 2.045 & $\begin{array}{l}4.381 \\
4.402 \\
4.423\end{array}$ & $\begin{array}{l}\text { AI } \\
\text { AII } \\
\text { AIII }\end{array}$ & $\begin{array}{l}\text { BIII } \\
\text { BI } \\
\text { BII }\end{array}$ & $\begin{array}{l}\text { CII } \\
\text { CIII } \\
\text { CI }\end{array}$ \\
\hline & & & 2.048 & $\begin{array}{l}4.382 \\
4.403 \\
4.424\end{array}$ & $\begin{array}{l}\text { AI } \\
\text { AII } \\
\text { AIII }\end{array}$ & $\begin{array}{l}\text { BIII } \\
\text { BI } \\
\text { BII }\end{array}$ & $\begin{array}{l}\text { CII } \\
\text { CIII } \\
\text { CI }\end{array}$ \\
\hline \multirow{3}{*}{$\begin{array}{c}\text { Afonso Pena } \\
\text { (Baía) } \\
\text { (1935) }\end{array}$} & \multirow{3}{*}{ V 114} & \multirow{3}{*}{1.324} & 2.087 & $\begin{array}{l}4.383 \\
4.404 \\
4.425\end{array}$ & $\begin{array}{l}\overline{A I} \\
\text { AII } \\
\text { AIII }\end{array}$ & $\begin{array}{l}\text { BIII } \\
\text { BI } \\
\text { BII }\end{array}$ & $\begin{array}{l}\text { CII } \\
\text { CIII } \\
\text { CI }\end{array}$ \\
\hline & & & 2.088 & $\begin{array}{l}4.384 \\
4.405 \\
4.426\end{array}$ & $\begin{array}{l}\text { AI } \\
\text { AII } \\
\text { AIII }\end{array}$ & $\begin{array}{l}\text { BIII } \\
\text { BI } \\
\text { BII }\end{array}$ & $\begin{array}{l}\text { CII } \\
\text { CIII } \\
\text { CI }\end{array}$ \\
\hline & & & 2.089 & $\begin{array}{l}4.385 \\
4.406 \\
4.427\end{array}$ & $\begin{array}{l}\text { AI } \\
\text { AII } \\
\text { AIII }\end{array}$ & $\begin{array}{l}\text { BIII } \\
\text { BI } \\
\text { BII }\end{array}$ & $\begin{array}{l}\text { CII } \\
\text { CIII } \\
\text { CI }\end{array}$ \\
\hline
\end{tabular}




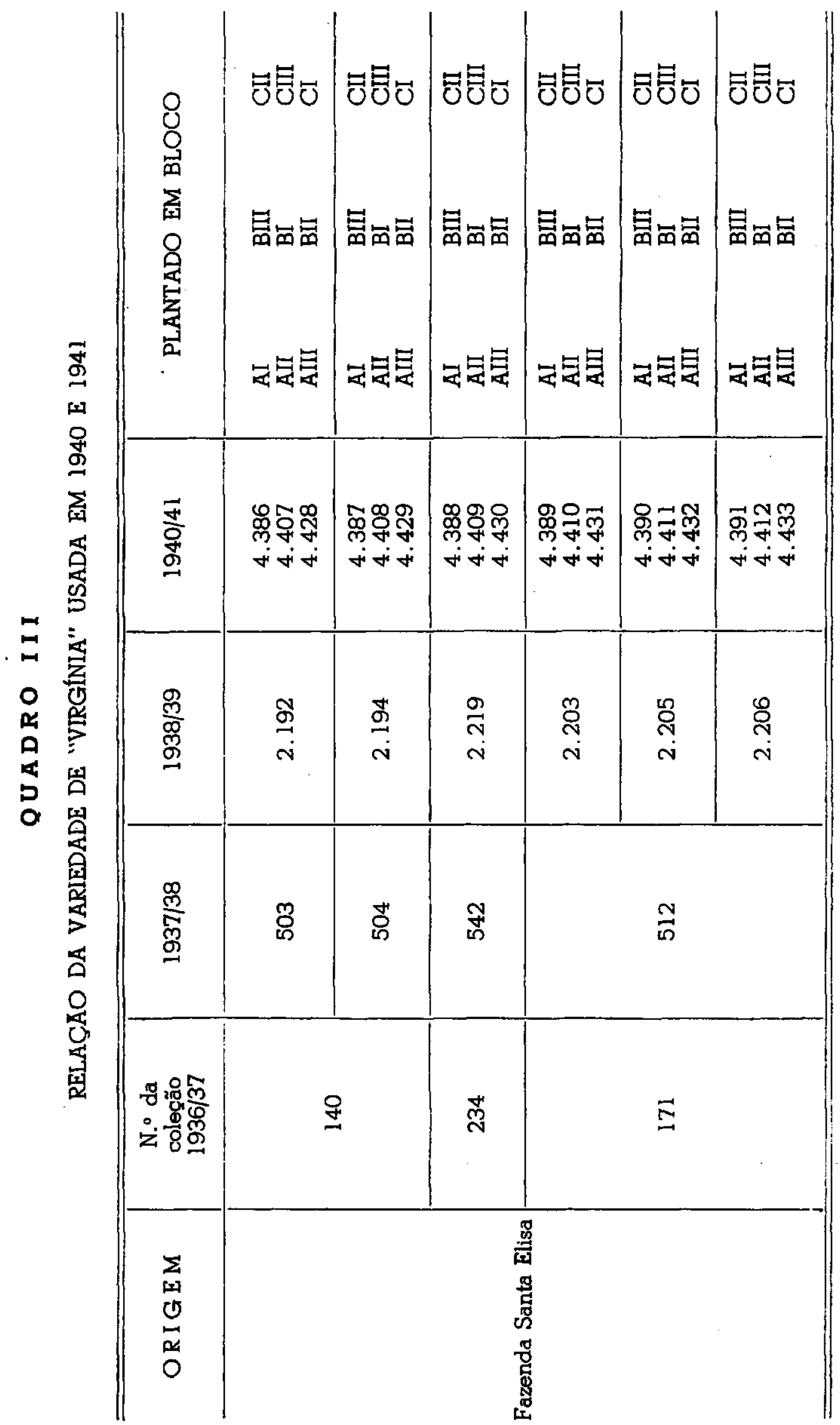




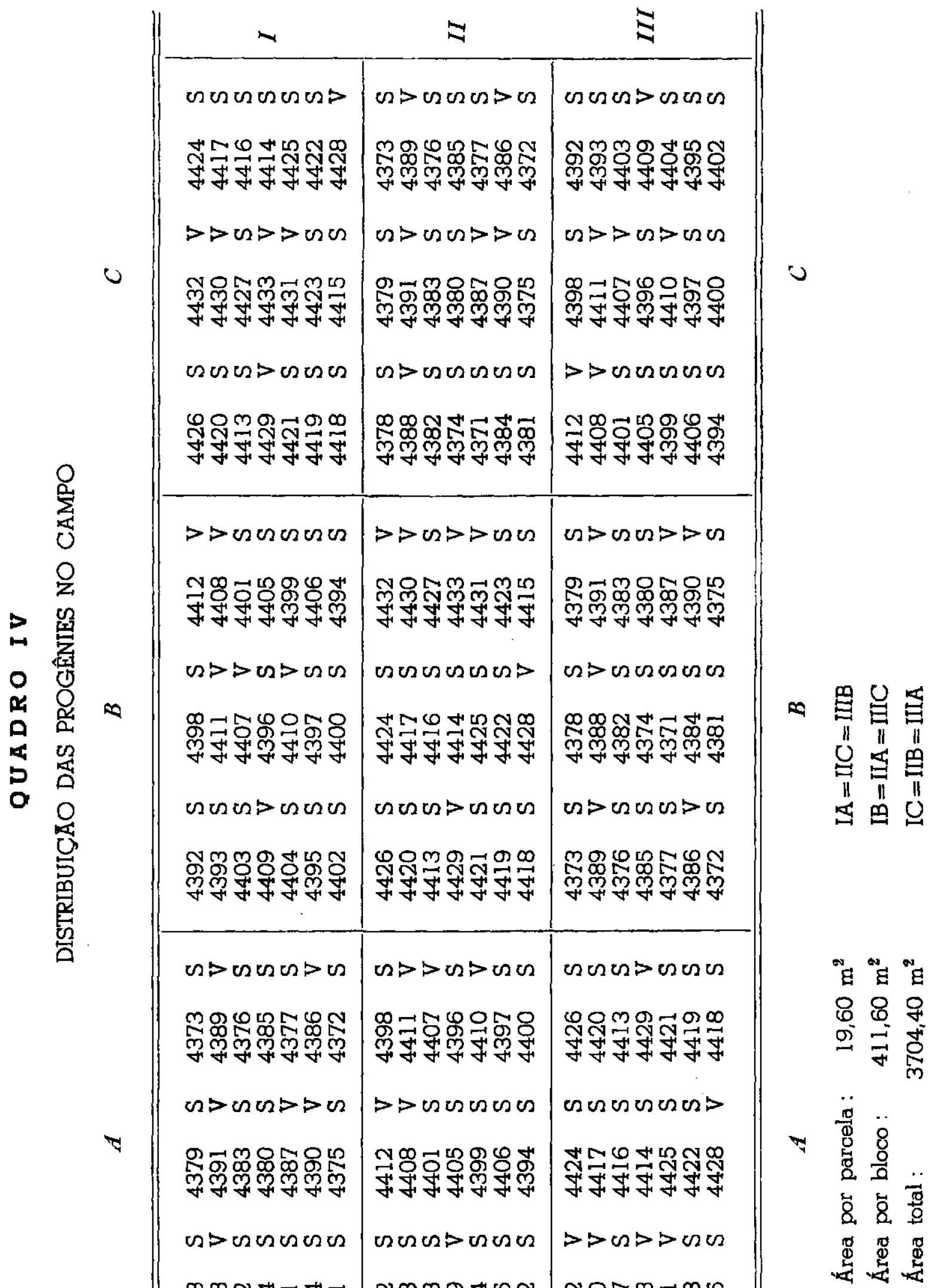




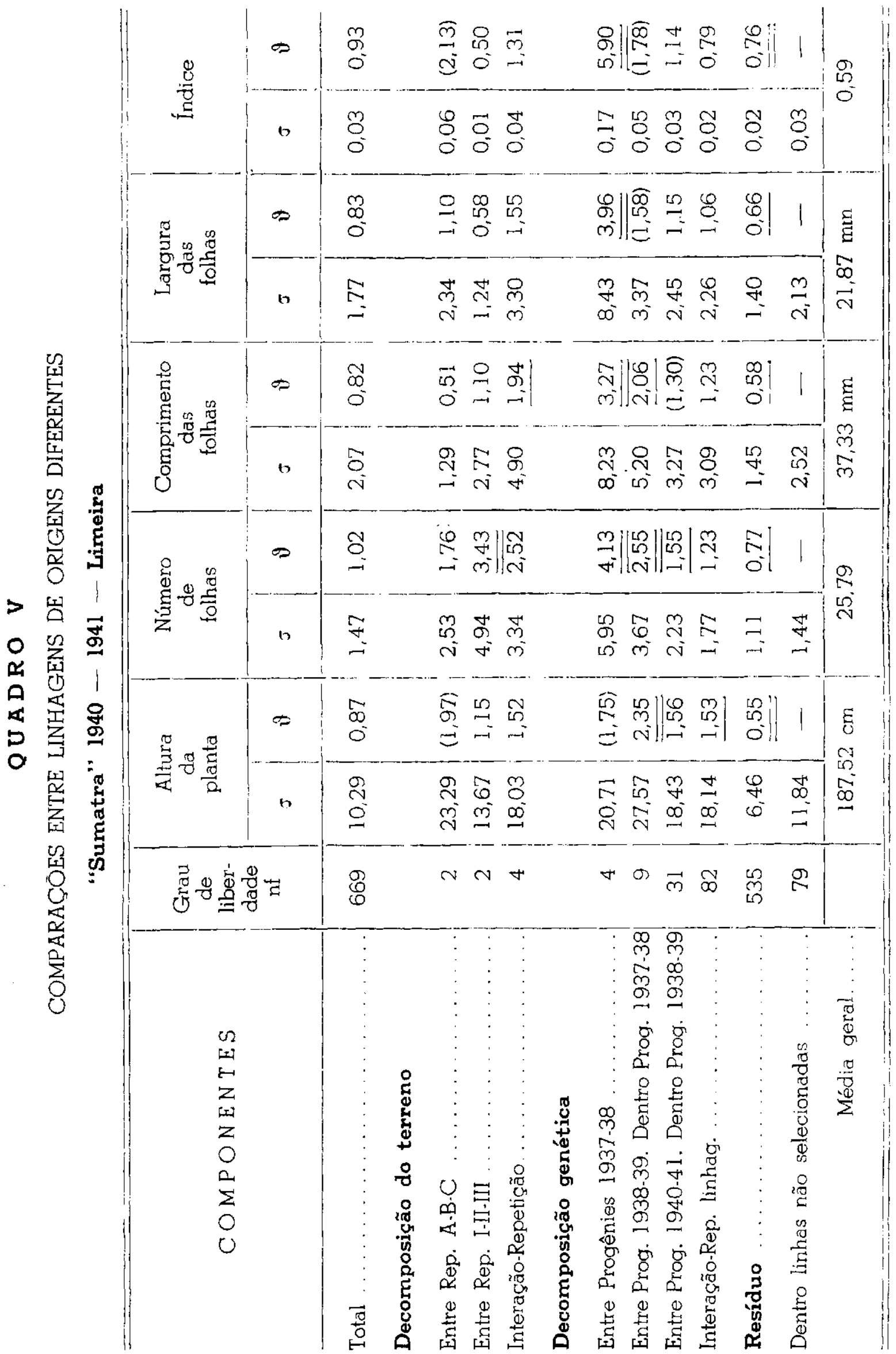




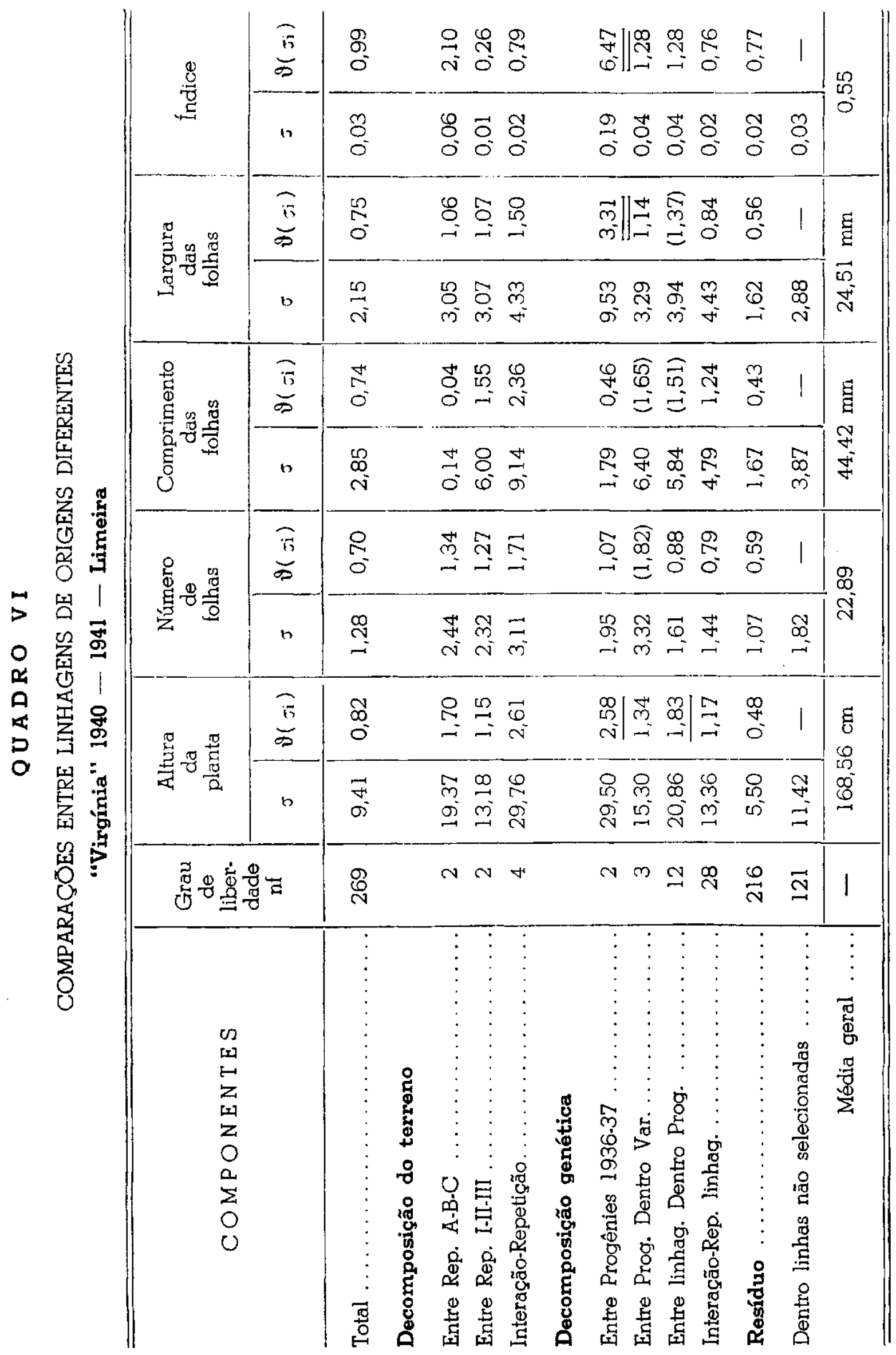




\section{QUA D R O V I I}

INFEÇAO COM VIRA-CABEÇA (PERCENTAGEM SOBRE "STAND" INICIAL)

\begin{tabular}{|c|c|c|c|c|}
\hline & \multicolumn{4}{|c|}{ SUM A T R A } \\
\hline & $\mathrm{nf}$ & $\sigma$ & $\begin{array}{c}\vartheta\left(\sigma_{p}\right) \\
(12,32)\end{array}$ & $\begin{array}{l}\vartheta\left(\sigma_{i}\right) \\
(8,15)\end{array}$ \\
\hline $\begin{array}{l}\text { Total } \ldots \ldots \ldots \ldots \ldots \ldots \ldots \ldots \ldots \ldots \ldots \text {. } \\
\text { Decomposição genética : }\end{array}$ & 131 & 12,48 & 1,01 & 1,53 \\
\hline Entre varied. . . . . . . . . . . . & 4 & 6,31 & 0,51 & 0,77 \\
\hline Entre progên. Dentro var. ........ & 9 & 13,08 & 1,06 & 1,60 \\
\hline $\begin{array}{l}\text { Entre linhag. Dentro progên. ....... } \\
\text { Decomposição do terreno }\end{array}$ & 30 & 11,31 & 0,92 & 1,39 \\
\hline Entre linh. & 2 & 18,97 & 1,54 & 2,33 \\
\hline Entre colunas $\ldots \ldots \ldots \ldots \ldots \ldots \ldots$ & 2 & 18,61 & 1,51 & 2,28 \\
\hline Interação $\ldots \ldots \ldots \ldots \ldots \ldots \ldots \ldots$ & 4 & 18,14 & 1,47 & 2,23 \\
\hline Resíduo $\sigma_{p} \ldots \ldots \ldots \ldots \ldots$ & 80 & 12,32 & - & 1,51 \\
\hline Erro ideal $\sigma_{\mathrm{i}} \ldots \ldots$ & - & 8,15 & - & - \\
\hline Média geral & & 63,95 & & \\
\hline
\end{tabular}


QUADRO VIII

VIRA-CABEÇA

Plantas sãs. "Virgínia" - Campinas

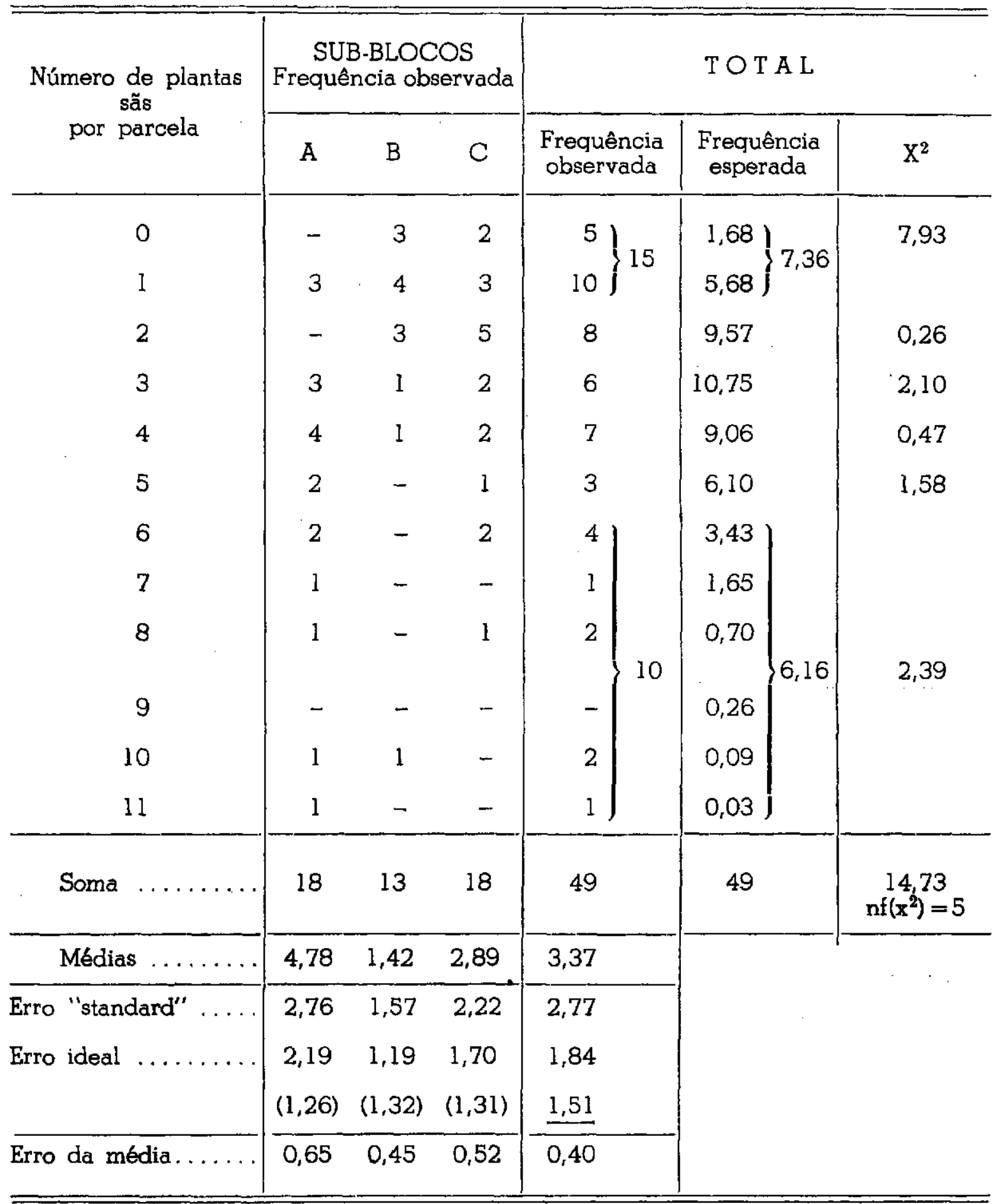

$$
\begin{aligned}
& t(\bar{v} A-\bar{v} B)=4 \\
& t(\bar{v} A-\bar{v} C)=(2,28) \\
& t(\bar{v} B-\bar{v} C)=(2,13)
\end{aligned}
$$




\section{QUADRO I X}

VIRA-CABEÇA

Plantas doentes, Limeira

\begin{tabular}{|c|c|c|c|c|c|c|}
\hline \multirow{3}{*}{$\begin{array}{c}\text { DOENTES } \\
\text { POR } \\
\text { FAMILIA }\end{array}$} & \multicolumn{3}{|c|}{ "SUMATRA" } & \multicolumn{3}{|c|}{ "VIRGÍn I A" } \\
\hline & \multicolumn{2}{|c|}{ Frequência } & \multirow{2}{*}{$X^{2}$} & \multicolumn{2}{|c|}{ Frequência } & \multirow{2}{*}{$\mathrm{X}^{2}$} \\
\hline & observạda & esperada & & observada & esperada & \\
\hline $\begin{array}{l}0 \\
1 \\
2 \\
3 \\
4 \\
5 \\
6 \\
7 \\
8 \\
9 \\
\end{array}$ & $\begin{array}{c}91 \\
36 \\
4 \\
1 \\
- \\
- \\
= \\
= \\
= \\
=\end{array}$ & $\begin{array}{c}92,6 \\
34,2 \\
6,3 \\
1,3 \\
0,1 \\
- \\
- \\
- \\
- \\
- \\
\end{array}$ & $\begin{array}{l}0,03 \\
0,42 \\
0,95\end{array}$ & $\left.\begin{array}{r}12 \\
18 \\
12 \\
5 \\
2 \\
3 \\
1 \\
- \\
-1\end{array}\right\} 7$ & $\begin{array}{r}9,3 \\
16,4 \\
14,4 \\
8,4 \\
3,7 \\
1,3 \\
0,4 \\
- \\
- \\
-\end{array}$ & $\begin{array}{l}0,78 \\
1,56 \\
3,36 \\
1,38 \\
\\
0,25\end{array}$ \\
\hline Soma ...... & 134 & 134,5 & $\begin{array}{c}1,40 \\
n f\left(X^{2}\right)=2\end{array}$ & 54 & 53,9 & $\begin{array}{c}7,35 \\
\mathrm{nf}\left(\mathrm{X}^{2}\right)=4\end{array}$ \\
\hline Média & \multicolumn{3}{|c|}{0,37} & \multicolumn{3}{|c|}{1,76} \\
\hline $\begin{array}{l}\text { Erro } \\
\text { "standard" } \sigma \\
\text { Erro } \\
\text { ideal } \sigma_{\mathrm{i}} \ldots \\
\vartheta=\sigma: \sigma_{\mathrm{i}} \ldots\end{array}$ & \multicolumn{3}{|c|}{$\begin{array}{l} \pm 0,58 \\
\pm 0,61\end{array}$} & \multicolumn{3}{|c|}{$\begin{array}{l} \pm 1,78 \\
\pm 1,36\end{array}$} \\
\hline Erro da média. & \multicolumn{3}{|c|}{ $\pm 0,05$} & \multicolumn{3}{|c|}{ $\pm 0,24$} \\
\hline
\end{tabular}

t ("Virgínia" -- "Sumatra") $=\underline{\underline{5,56}}$ 